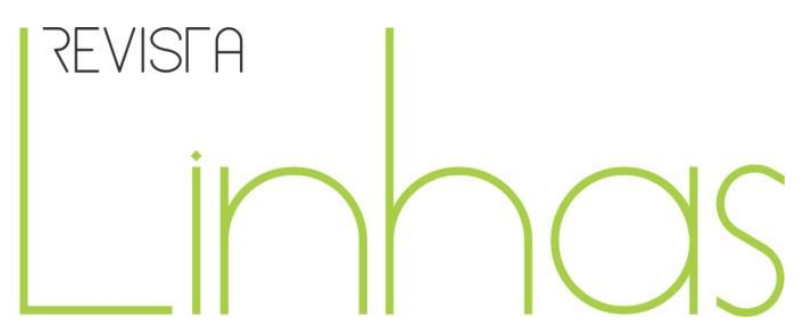

\title{
Resenha do livro "A Escola como cultura: experiência, memória, arqueologia”
}

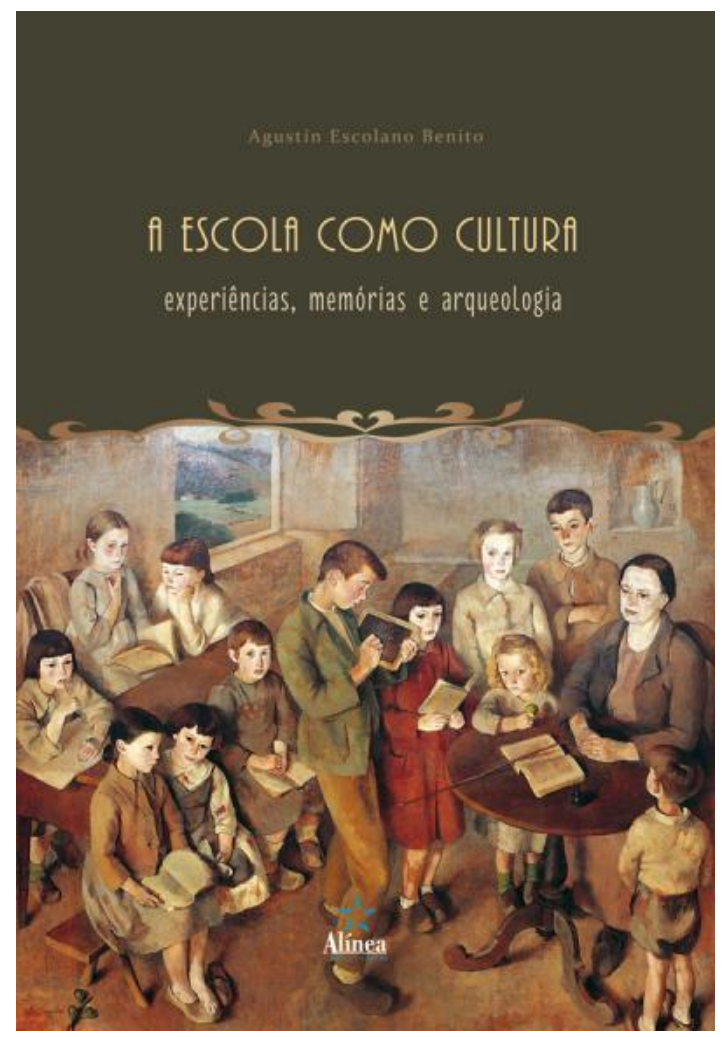

BENITO, Agustín Escolano. A Escola como cultura: experiência, memória, arqueologia. Ed. Alínea, 2017. $282 \mathrm{p}$.

Franciele Ferreira França

$$
\begin{gathered}
\text { Universidade Federal do Paraná - UFPR - Brasil } \\
\text { fran.f.franca@outlook.com }
\end{gathered}
$$

\section{Para citar esta resenha:}

FRANÇA, Franciele Ferreira. Resenha do livro "A Escola como cultura: experiência, memória, arqueologia". Revista Linhas. Florianópolis, v. 18, n. 38, p. 375-380, set./dez. 2017. 
“São nossas paixões que desenham nossos livros, e o intervalo de repouso que os escreve"”.

Lida por acaso, a frase anterior pode indicar muitos sentidos, muitas interpretações, alguns bem distintos daquele tomado por quem a escreveu. Mas, é preciso que nos concentremos no significado que ela ganha ao ser escolhida como epígrafe de um trabalho sensível e denso acerca da escola, seus sujeitos, sua materialidade, sua história e sua cultura. Esta passagem, retirada de uma das obras de Marcel Proust, aos poucos, passa a ter um significado peculiar no estudo feito e apresentado por Agustín Escolano Benito em seu livro A escola como cultura: experiência, memória, arqueologia; um sentido que aparece diluído em cada item e assumido em cada capítulo, mas visível somente se tivermos olhos para ver.

Neste trabalho em que, nas palavras de Diana Vidal (no prefácio da obra), "não lhe falta rigor teórico, mas sobeja a delicadeza que entrelaça vivências do autor ao exercício refinado do pensamento científico" (p. 07), o tema que se desenvolve parte de uma “inquietação" que tem acompanhado Escolano Benito ao longo de sua trajetória como professor, historiador e teórico do campo da educação - identificar e compreender a racionalidade embutida na cultura empírica presente nas instituições de formação. Uma preocupação que o tem levado "a buscar, obstinadamente, uma explicação reflexiva sobre a lógica subjacente às práticas que via, diariamente, os outros docentes executarem em suas salas de aula" (p. 21) e a si mesmo. Contudo, para além de encontrar uma explicação para a conduta empírica dos atores da educação, Escolano Benito aspira ainda poder decifrar os códigos incutidos nas ações manifestadas por esses sujeitos e interpretar as significações e os sentidos destas. O interesse recai também em compreender a influência cultural sobre a forma como o universo material que compõe as instituições de formação foi definido e aceito no decorrer dos anos. Em um olhar atento para sua produção intelectual ${ }^{2}$ é possível perceber o quanto o autor se dedica ao estudo

\footnotetext{
1 "Son nuestras pasiones las que diseñan nuestros libros, y el intervalo de reposo el que los escribe". PROUST, Marcel. De la imaginación y del deseo. Editorial: Península, 2001.

2 Exemplos de alguns dos trabalhos do autor que discutem o tema: ESCOLANO BENITO, Agustín. La construcción histórica de la escuela desde la lógica de la razón práctica. Q. Times, Revista online, Roma, año V, n. 01, 2013. ESCOLANO BENITO, Agustín. La cultura empírica de la escuela. Aproximación etnohistórica y hermenéutica. In MAINER, Juan (ed.): Pensar críticamente la educación, Zaragoza, Prensas de Zaragoza, 2008, pp. 158-159. ESCOLANO BENITO, Agustín (ed.). La cultura material de la escuela. En el centenario de la Junta para Ampliación de Estudios, 1907-2007, Berlanga/Soria, CEINCE, 2007. ESCOLANO BENITO, Agustín.
} 
dessa temática, e, se num conjunto expressivo de trabalhos Escolano Benito já nos conduzia à reflexão sobre a escrita da história da escola, neste livro o autor não só retoma esta "preocupação", como se debruça sobre ela maturando e aprofundando a análise.

$\mathrm{Na}$ escrita dos quatro capítulos que compõem o livro, nos é feito o convite a adotar uma outra abordagem para o estudo do passado, mais precisamente para o estudo da escola do passado interligada à escola do presente. Como um historiador erudito, ancora-se em uma perspectiva que alia a Sociologia, a Filosofia, a Antropologia e a História, transitando com perícia por esses campos. Ao manejar com destreza os conceitos, o autor nos dirige pelos caminhos trilhados em sua investigação sobre a história e a cultura da escola sob um olhar que ele mesmo define como arqueológico, "sustentada no estudo das materialidades, de seus usos institucionais e do valor narrativo que os atores lhe atribuem" (p. 26). Partindo de uma reflexão fundamentada em documentos e análises sócio-históricas, defende que a experiência seja tomada novamente como uma fonte essencial para o conhecimento do passado para que se possa sustentar a construção de uma cultura escolar pragmática e plausível. Nesta inversão investigativa, operacionalizada "mediante uma imersão etnográfica, intuitiva e fenomenológica", a experiência emerge como fonte primária e a materialidade ganha maior destaque na e para a constituição dos saberes acerca da escola e da formação em geral.

Quanto à organização interna, o conteúdo do livro se concentra e se distribui em quatro eixos temáticos: a experiência, a cultura, a memória e a arqueologia; os quais intitulam os quatro capítulos que o compõem.

No primeiro capítulo, o autor entabula uma discussão sobre o "mundo da prática, ou da experiência" configurado no interior das escolas, dialogando principalmente com Pierre Bourdieu, nas teorias sobre as dinâmicas e os mecanismos que constituem as práticas dos agentes sociais ${ }^{3}$. Escolano Benito sugere um giro epistemológico e historiográfico na análise de um passado da escola, com base em uma concepção de experiência que ressignifica e fundamenta uma cultura escolar concretizada em ações,

Las culturas escolares del siglo XX: Encuentros y desencuentros. Revista de Educación, número extraordinario, 2000, pp. 201-208.

${ }^{3}$ BOURDIEU, Pierre. El sentido práctico. Madrid: Siglo XXI, 2007. 
discursos, sujeitos e objetos, tratando-a como uma "espécie de techne de que fala Richard Sennett, a qual conforma a sabedoria prática das profissões certificadas; mescla de tradição sedimentada do trato direto com a realidade e de criação ou poiesis de novas propostas" (p. 29-30). Em uma crítica sutil, o autor afirma que muitos dos estudos historiográficos acerca da escola, pautados por uma perspectiva positivista, desconsideram a experiência como fonte, o que tem provocado um silenciamento de aspectos significativos sobre a história da educação. Ao indicar e estabelecer diálogo, ao longo de todo o capítulo, com outros trabalhos que valorizam o mundo prático da escola, apontando suas contribuições para o conhecimento do processo histórico da educação, faz o que podemos adjetivar como um extenso trabalho de "estado da arte", num contraponto à perspectiva anterior.

Se na primeira parte do livro, Escolano Benito demonstra, junto da bibliografia, como foi se constituindo a arte de ensinar, o ofício docente e a "aventura de aprender" por meio da experiência, no segundo capítulo, o autor procura evidenciar a potencialidade desta como fonte para a cultura escolar. Neste capítulo, o intuito é identificar os componentes que formam a prática, ou seja, o autor busca discernir que cultura é essa que configura e se forma do e no exercício docente e que conforma o espaço escolar. Para tanto, apresenta as contribuições recentes do campo da História Cultural e dos estudos etnográficos e hermenêuticos sobre a cultura da escola e procede uma discussão acerca dos modos de "compreender, explicar e interpretar a experiência e suas representações" (p. 108). Apoiado nesse diálogo, o autor destaca que a historiografia recente já constata que esta cultura da prática tem sobrevivido nas instituições de formação e que a mesma constitui atualmente um dos "nós górdios a serem desfeitos para se compreender os silêncios e os códigos que, em parte, autorregulam o mundo da educação institucionalizada" (p. 115). Com base em estudos de Stuart Hall e Anthony Guiddens, desenvolve a concepção de cultura que norteia seus estudos, articulando-a ao conceito de habitus utilizado por Pierre Bourdieu e Norbert Elias, adentra e explora a complexa gramática da escolarização acenada pelos estudos de Larry Cuban e David Tyack, e ainda discorre sobre o tato pedagógico abordado nas reflexões de Georg Kerchensteiner, Hans G. Gadamer e Max Van Manen; conceitos que se unem e 
fundamentam a tese defendida por Escolano Benito acerca do seu objeto de estudo ao logo do trabalho.

“Para além do tato e da phronésis, está a experiência sedimentada, expressa em linguagem narrativa e constituída em memória” (p. 155). Partindo desta premissa, Agustín Escolano Benito centra a análise do terceiro capítulo na "experiência sedimentada constituída em memória", ou seja, volta-se para a cultura escolar examinando-a como memória. Desta forma, propõe-se a ponderar sobre o valor das recordações e os conteúdos que essa memória arquiva, considerando a influência organizacional da escola nos sujeitos a ela submetidos. Assim, "analisa igualmente o papel da memória na fixação das práticas de sociabilidade (...) e na criação de estereótipos acerca da imagem dos docentes" e lista e define "os registros guardados pela memória acerca das materialidades com que se instrumentalizou a pragmática escolar" (p. 178). É importante observar que Escolano Benito constrói sua narrativa de forma encadeada e entrelaçada; conceitos, assuntos e argumentos discutidos e mencionados, são constantemente retomados e ganham certo refinamento analítico enquanto o autor avança e se concentra na bibliografia e nas fontes nas quais se apoia. Deste modo, "materializa" sua ideia de que os testemunhos das coisas e das pessoas, pertencentes ao universo escolar, compõem um patrimônio material e imaterial legado a nós pelo passado ${ }^{4}$. A reflexão é ilustrada com a narrativa de um experimento realizado no Centro Internacional de Cultura Escolar (CEINCE) com idosos afetados pela senilidade e mal de Alzheimer - um projeto sensível que revela o quanto temos da escola em nós. Assim, delineia um estudo indicando novas possibilidades de pesquisa, usos de conceitos passíveis de serem operacionalizados e perspectivas a serem seguidas no trato, exame, validação e valoração da memória, que ganha novos e ampliados contornos como fonte, objeto, abordagem e conceito de análise.

No último capítulo, somos levados por um caminho pavimentado por vestígios materiais da escola. A partir de situações vivenciadas com e por pessoas com quem esteve em contato, Escolano Benito esboça um ensaio sobre a memória da escola sob um olhar arqueológico e nos demonstra como a materialidade escolar é significativa para o conhecimento dos saberes que permeiam, configuram e conformam estas instituições.

\footnotetext{
${ }^{4}$ Uma ideia que entremeia toda a discussão da obra.
} 
"Como fontes da cultura da escola, tais restos guardam segredos que afetam os silêncios da história da educação e da gramática que codificou a escolarização" (p. 223). Aqui, o autor anuncia os vestígios materiais da escola como "objetos informadores" que desvelam silêncios do passado, os quais podem ser considerados como informantes reais, seguros e confiáveis que nos contam sobre as instituições, as práticas executadas pelos docentes e alunos, as teorias pedagógicas determinantes das atividades didáticas que se apoiaram na utilização do objeto ou documento (p. 225).

Vale destacar que, ao longo de toda a obra, Agustín Escolano Benito nos proporciona um amplo e vasto repertório bibliográfico sobre a temática, que seguramente poderá servir de fundamentação para novas pesquisas em história da educação. Além disso, o autor, ao se debruçar sobre conceitos-chave que ancoram os estudos sobre o passado da escola, desmonta-os, apresentando-nos sua estrutura para reconstruí-los sob uma nova perspectiva. Empreende ainda uma reflexão sobre o ofício do historiador da educação, problematizando o tratamento historiográfico no cotejamento das fontes com a bibliografia. Com ferramentas deste porte, nos conduz do presente ao passado e do passado ao presente, mesclando "realidade" e ficção (pelo uso da literatura), intercalando imagens, personagens e experiências em uma narrativa que nos recomenda algumas reflexões e nos instiga a travar confrontos com o passado e o presente para a construção de um conhecimento sobre o processo histórico da escola.

Para finalizar, posso afirmar, ao fim da leitura, que, muito mais do que uma “inquietação”, o que moveu o desenho deste livro foi a "paixão" de Escolano Benito por seu ofício como historiador e como praticante da arte de ensinar e o repouso traduz-se na experiência acumulada por ele ao longo da sua trajetória.

Recebido em: 07/11/2016 Aprovado em: 11/09/2017

Universidade do Estado de Santa Catarina - UDESC Programa de Pós-Graduação em Educação - PPGE Revista Linhas

Volume 18 - Número 38 - Ano 2017 revistalinhas@gmail.com 